\title{
Tactical Capacity Planning in Hospital Departments
}

Agneta Larsson and Anna Fredriksson

The self-archived postprint version of this journal article is available at Linköping University Institutional Repository (DiVA):

http:// urn.kb.se/ resolve?urn=urn:nbn:se:liu:diva-153098

N.B.: When citing this work, cite the original publication.

Larsson, A., Fredriksson, A., (2019), Tactical Capacity Planning in Hospital Departments, International J ournal of Health Care Quality Assurance, 32(7), .

Original publication available at:

Copyright: Emerald

http:// www.emeraldinsight.com/ 


\section{Tactical capacity planning in hospital departments}

Author 1: Agneta Larsson, PhD Candidate, Technology Management and Economics, Chalmers University of Technology, Gothenburg, Sweden, +46 3177251 52, agneta.larsson@chalmers.se

Author 2: Anna Fredriksson, Assistant Professor, Department of Science and Technology, Linköping University, Norrköping Sweden, +46 $11 \quad 36 \quad 33$, anna.fredriksson@liu.se

\section{Corresponding Author: Agneta Larsson}

Corresponding Author's e-mail: agneta.larsson@ chalmers.se

Purpose: This article explores tactical planning potential within hospital departments. The study adopts two objectives: first, to develop a framework for tactical capacity planning in healthcare departments by identifying and structuring essential components for healthcare capacity management, and, second, to identify context-specific requirements and functionality demands on tactical planning processes within healthcare.

Methodology: A framework for tactical capacity planning was developed through a literature review. Additionally, an exploratory multiple-case study was performed, with cases from three Swedish hospital departments, which provide the opportunity to study framework applicability in its natural context.

Findings: Findings illustrate how an active tactical planning process can facilitate adjustments to capacity. However, the multiple-case study shows that there are contextual differences between departments depending on treatments and resources available that affect possible capacity adjustments, and how the planning process activities should be structured.

Originality: This project develops a framework for a tactical capacity-planning process adapted to healthcare provider contexts. By developing the framework based on the literature and tactical level planning processes within three Swedish hospital case study departments, we bridge gaps between theory and application regarding healthcare capacity planning.

Keywords: Capacity planning; Healthcare; Hospital tactics; Planning process

Article Classification: Research

Received $-21^{\text {st }}$ Nov 2017

Revised $-13^{\text {th }}$ April 2018

Accepted -

\section{Introduction}

The Swedish Ministry of Finance (Finansdepartementet, 2010) and the OECD Economics Department (Rae, 2005; OECD, 2016) report that the Swedish healthcare system medical quality is performing well. However, in comparison to other Nordic countries, Swedish hospitals have the lowest productivity (Stiernstedt et al., 2016a; Stiernstedt et al., 2016b). One reason behind this is capacity management challenges, evident as staff numbers continue to increase, while the production rate remains stable (Stiernstedt et al., 2016a; Stiernstedt et al., 2016b). Capacity management challenges have also been noted in the United Kingdom (Silvester et al., 2004), the Netherlands (Vissers et al., 2001; Hans et al., 2011), Australia, Canada, New Zealand, and Belgium (Willcox et al., 2007; Cardoen et al., 2010b). To deal 
with these capacity management challenges, Silvester et al., (2004) suggests that healthcare capacity-planning processes need to better balance resource supply and patient demand.

Capacity planning processes are hierarchically structured following the following production planning levels: strategic, tactical, and operational (Jack and Powers, 2009; Rhyne and Jupp, 1988; de Vries et al., 1999; Roth and van Dierdonk, 1995). Strategic planning has a long-term horizon and sets the boundaries for the mid-term horizon tactical planning, which sets the boundaries for the short-term horizon operative planning (Jonsson and Mattsson, 2009). Tactical planning processes in manufacturing companies are seen as a key process enabling holistic planning by balancing demand and supply, and enforcing integration and coordination among departments, business strategy, operational planning and in the supply chain.

Larsson and Johansson (2007), Roth and van Dierdonk (1995) and Hans et al., (2011) attribute healthcare operational challenges to insufficient tactical planning. Improved production planning and implemented tactical capacity-planning processes help to stabilise operational performance and decrease the risk that insufficient resources and long wait times for patients are addressed with costly short-term fire-fighting adjustments (Hans et al., 2011). Within healthcare organisations, tactical planning is often the department manager's responsibility (Vissers et al., 2001). However, as it is now, department managers receive little support with processes and tools.

Earlier research on hospital capacity planning focused on operational planning (Jack and Powers, 2009; Ridge et al., 1998; Cardoen et al., 2010a; Adan and Vissers, 2002), including patient mix (Adan and Vissers, 2002) and scheduling (Cardoen et al., 2010a). Hospital planning process studies primarily present planning and control frameworks including all planning levels (strategic, tactical and operational) (Vissers et al., 2001; Hans et al., 2011; Rhyne and Jupp, 1988). The step-by-step approaches to tactical planning that are available within the literature (Hernándes et al., 2008; Tavares Thomé et al., 2012) have not been developed for the healthcare context, resulting in little understanding regarding how to apply these approaches in a healthcare setting. Tuomikangas and Kaipia (2014) call for contextualised empirical research to provide tactical planning implementation guidelines, and Ivert et al., (2015) show that to improve the tactical planning potential in a specific setting, the process must be adapted to the context in question. Coming to practice, in Sweden several healthcare providers started to consider production planning around 2012 as a response to a government demand. Though, as it has been hard to find planning processes adapted to the health care context has the implementation been slow. Consequently, to provide department managers with support in innovating structured tactical planning processes and further developing existing ones, there is a need for complementary research on healthcare tactical planning processes. Thus, our purpose is to explore tactical planning potential within hospital departments. To fulfil this purpose, we adopt two objectives:

- to develop a framework for healthcare tactical capacity planning by identifying and structuring essential healthcare capacity management components

- to identify context specific requirements and functionality demands on tactical planning processes within hospital departments

\section{Methodology}

The first objective is fulfilled through a literature review involving on healthcare capacity management and capacity planning books and journal articles, identifying tactical healthcare capacity-planning components and outputs. From among the existing tactical planning frameworks (Tavares Thomé et al., 2012; Hernándes et al., 2008), the Tavares Thomé et al., 
(2012) framework was selected in line with Ivert et al's (2015) reasoning to structure the identified process components and outputs. First, the framework by Tavares Thomé et al., (2012) follows a general process structure and, second, it considers tactical planning. According to Tavares Thomé et al., (2012), planning processes include the procedural structure and activities, inputs and outputs (Figure 1). To have a framework that balances required and available capacity, we added the 'adjustments' component, which includes alternatives for reducing gaps between supply and demand for capacity.

\section{Figure 1 here}

To fulfil the second objective, we performed an exploratory multiple-case research approach, with cases from three Swedish university hospital departments (cardiology, urology and psychiatry). The case study research format enabled us to study the phenomenon in its natural context and use existing experiences (Barratt et al., 2011). Our study is based on contingency theory, that is, the context and structure must fit together if the organization is to perform well (Drazin and Van de Ven, 1985). Contingency theory helps scholars question the current research stream within operations management, focusing on best practices by showing the context dependencies (Sousa and Voss, 2008). The study focus is the tactical planning process performed by hospital departments since it is at this level that the tactical balancing (planning horizon about 12 months) between resource supply and demand takes place. Departments were selected based on their differences in care processes. Different resource types give different opportunities regarding capacity adjustments. However, since healthcare capacity planning is relatively immature compared to the manufacturing industry, it was also necessary to evaluate maturity levels to separate specific contextual requirements and pure immaturity. Although Grimson and Pyke (2007) presented a well-developed planning maturity framework, we chose an elementary framework presented by Lapide (2004) because process maturity is not the primary focus and an elementary framework was sufficient to understand variation in component content not caused by immaturity. Table I shows the Lapide (2004) four stage framework: marginal, rudimentary, classic and ideal.

\section{Table I here}

Data collection included semi-structured interviews, following an interview guide based on Figure 1 (Halvorssen, 1992). Consistent with this structure, data collection focused on identifying the primary structure and activities, inputs, outputs and adjustments in department tactical capacity planning. The three interviewees were department managers, and each was interviewed three times over a month. Complementary data were collected during interviews with unit managers and administrative staff. For the urology department's planning process, staff at the central operation department were also interviewed to better understand how resources were coordinated between the department and the operating theatre. One researcher performed all interviews. Information was validated by respondents reviewing the transcripts; i.e., member checking, and opportunities to correct any misunderstandings during follow-up interviews were also possible.

As commonly suggested in case study research (Barratt et al., 2011), a first case analysis was done by analysing each case description, followed by cross-case analysis to identify department context-specific requirements and functional demands. The within-case analysis was made by organising case data according to the developed framework, which also enabled us to visualise the framework's applicability to capturing healthcare tactical capacity planning's main components, thus helping to answer the first research objective as well. 


\section{Departments and their capacity management challenges}

The cardiology departments have approximately 40 physicians, 250 nurses and administrative staff, who treat roughly 16,900 outpatients and 6,000 inpatients annually. The department has three wards, six laboratories, an outpatient polyclinic, divisions for heart conditions and smoking cessation, and a teaching unit. Urology department staff treat approximately 22,000 patients annually and performs about 1,300 inpatients surgeries and 5,000 polyclinic surgeries, mostly on cancer patients. The department includes two wards and an outpatient clinic, with eight receptions, each with its own speciality, such as prostate cancer, colostomy, kidney cancer, or kidney stones. Third, the psychiatry department specialises in affective disorders and differs from the others by having nine outpatient clinics at different locations with varying specialisations. The department also has five hospital wards for inpatient care and another for research and teaching.

The cardiology department's capacity management challenges include patients' acute conditions and an immature planning process. Most patients with acute conditions require the production system to react and provide care rapidly. Patients not offered treatment quickly are entitled to seek treatment at private healthcare providers, which cost 2.5 times as much as public providers; the cost coming from the department's budget and thus limiting its financial resources. Immature planning resulted in staff schedules were un-coordinated, which caused problems such as nurses sitting idle when physicians were attending seminars or conferences. Within the urology department there has been specialised staff shortage and low efficiency in the planning process, because the organisation was not synchronised with necessary changes owing to inertia and a slow-moving bureaucracy. The psychiatry department has experienced input data and mental disorder challenges. Estimating how many visits a patient with a specific disorder would be needing, requires a standard treatment procedure for that particular patient group, however historical data were unavailable, and the treating physicians have to make such decisions for themselves based on the disorder, because patients - especially those suffering from multiple disorders - can seldom be assigned to a certain group. Moreover, one disorder can cause other disorders to emerge, and precisely which disorder prompts a hospital visit is unclear from the administrative systems statistics.

\section{Tactical capacity planning within healthcare}

\section{Structure and activities}

How the planning process is performed, is based on its structure and activities (Tavares Thomé et al., 2012). Structure organises which activities are performed, how, and when, and indicates the data analysis methods. During planning, meetings can be characterised as to their frequency - usually monthly or quarterly - and their participants, who should all be empowered to make decisions (Tavares Thomé et al., 2012; Lapide, 2004). At the tactical level, decisions concern the planning object, such as product or service group (Vissers et al., 2001; Jonsson and Mattsson, 2009; Adan and Vissers, 2002; Tavares Thomé et al., 2012; Tai and Williams, 2008). The planning horizon at this level varies by organisation, depending on product or service lead times (Grimson and Pyke, 2007), and can range from six to 18 months (Tavares Thomé et al., 2012).

Tactical planning process activities involve estimating demand for products or services, determining a preliminary delivery plan, and generating a preliminary master production schedule (MPS), reconciliation, conditions, and plan updates (Jonsson and Mattsson, 2009; Grimson and Pyke, 2007). The way in which data are analysed and combined in the process varies by organisation and can include, for example, analytical methods to support capacity planning that range from advanced information technology systems or mathematical models to spreadsheets. However, even the simplest method can sufficiently achieve its purpose (Jonsson and Mattsson, 2003). Current healthcare methods and calculation models can 
roughly be described as focusing on how to use resources effectively (Adan and Vissers, 2002) or how to redesign them to improve patient flows (Tai and Williams, 2008; Beliën and Demeulemeester, 2007). Research mentions different tools to support capacity planning decision-making (Ridge et al., 1998; Tai and Williams, 2008; Beliën and Demeulemeester, 2007; Utley and Worthington, 2012).

\section{Input}

Input concerns what to produce and what resources are needed to plan. The so-called roughcut capacity plan (Lapide, 2004) includes anticipated capacity variations (Silvester et al., 2004) necessary to balance planned production, where the planned production is based on unconstrained forecasts, with variations and consensus-based production plans (Silvester et al., 2004; Vissers et al., 2001; Lapide, 2004). These projections are made to provide a required capacity. Consensus-based production plans are critical to tactical planning to unify departmental and organisational goals. In businesses, consensus occurs among organisational functions (e.g., production, finance and sales), whereas in healthcare organisations, it occurs among production units that form a network through which patients pass during treatment.

Future demand includes both known and unknown claims (Hans et al., 2011); known includes waiting list information and patients currently in treatment, whereas the unknown is forecasted demand that is often based on historical data (Hans et al., 2011; Moore, 2003). Healthcare demand variation occurs in: volume (Utley and Worthington, 2012; Jack and Powers, 2004), resource-mix requirements (Adan and Vissers, 2002; Tai and Williams, 2008), urgency and patient throughput. Input concerning hospital capacity generally entails facilities, a workforce, and equipment (Jack and Powers, 2009). Within capacity management, the rough-cut capacity plan contrasts the balance with patient demand that is represented by a production plan. In healthcare organisations consensus-based rough-cut capacity plans can be used between the producing departments and units to achieve a crossfunctional balance (Tavares Thomé et al., 2012), thereby facilitating a smooth patient flow. This is especially important when resources are shared among many units or departments (Vissers et al., 2001; Adan and Vissers, 2002). Resource characteristics influence the capacity at which they can deliver (i.e., multifunctional or specialised) and how best to manage them. Capacity is often formulated as time and entities (de Vries et al., 1999). Using cost-intensive resources often results in attempts to achieve high resource utilization.

Strategic decisions, including departmental unit availability or available time in units, restricts the tactical plans from above, and the operational plan feasibility restricts them from below in the hierarchical planning structure (Adan and Vissers, 2002). Other restrictions can be financial, as in budgeting or if the hospital operates in a contracting market (Vissers et al., 2001; Tavares Thomé et al., 2012). Planning targets; e.g., formulated as patient throughput (i.e., time and volume) (Adan and Vissers, 2002), patient waiting time, waiting list length, resource use (Adan and Vissers, 2002), production costs (de Vries et al., 1999) and bed occupancy (Beliën and Demeulemeester, 2007) - involve measuring what healthcare providers anticipate achieving with the healthcare production system. Other than the capacity plan and unconstrained, consensus-based production plans, tactical capacity planning has to consider restrictions on the system, targets to achieve, and how current production plans conform to accepted variation in performance related to target values, or so-called tolerance levels. According to Tavares Thomé et al., (2012), tactical planning's main role is to warn about early supply and demand imbalance.

\section{Adjustments}

Adjustments are made through capacity allocation and acquisitions to balance demand and supply (Olhager et al., 2001; Eriksson et al., 2011). In healthcare, three resource types are 
involved in capacity adjustment decisions: workforce, equipment and facilities (Utley and Worthington, 2012; Smith-Daniels et al., 1988). Tactical resource acquisition involves decisions concerning workforce changes, overtime, extra staff and subcontracting (Utley and Worthington, 2012; Smith-Daniels et al., 1988), innovative shift schedules and employee cross-training to accommodate movement among units (Jack and Powers, 2004). Adjusting patient demand can entail patient prioritisation according to medical condition, rescheduling, queues, admissions planning and scheduling rules (Adan and Vissers, 2002).

\section{Output}

Capacity planning's chief goal is ensuring feasible production plans (Tenhiälä, 2011), production system constraints and demands. Other than production plans, output should link lower and higher planning levels by providing feedback on tactical plan feasibility, that is, problems that occur during plan execution, which will help to improve hospital management (Butler et al., 1996) and the healthcare delivery effectiveness and efficiency (Hans et al., 2011). Linking can also make managers less reactive and more proactive to changes (Butler et al., 1996). The production plan output and actual outcomes provide the planning system with feedback on plan feasibility planning for the next round, and accurate demand forecast (Lapide, 2004).

\section{Table II here}

\section{Analysis}

Case analysis - cardiology, urology and psychiatry

Structured capacity-planning process

Cardiology's poorly structured process and cost-intensive production system has characterised planning as a budgeting tool, not a planning support system. Urology proactively uses tactical capacity planning to identify deficiencies in capacity or production backlog in advance, chiefly to afford the manager control and show whether production proceeds according to plan. Planning also entails activities in response to deviation from the plan; e.g., when operation waiting time is too long. Potential improvements in the planning process include reduced bureaucracy. Psychiatry's current capacity-planning involves a planning process designed to support the department's complex production structure, so far by dividing planning between the clinics and having a comprehensive planning process for all psychiatric healthcare. Staff scheduling occurs quarterly in all departments.

\section{Meeting frequency}

Meetings occur monthly in urology and psychiatry and yearly in cardiology. A monthly recurrent meeting can sufficiently forecast capacity surplus, while annual meetings cannot.

\section{Meeting participants}

In all three departments, cross-functional participation - a departmental manager, unit and section managers (if applicable), and a representative providing data - can adequately complete capacity planning. During capacity-planning, cardiology and psychiatry included planning support at the meetings. Focused on budgeting, cardiology's meetings include a human resource representative and an economist. In urology, capacity-related changes would benefit from a senior representative mandated to approve such changes to decrease the lead times for implementing capacity adjustments.

\section{Planning horizon}


All three departments have 12-month planning horizons; urology and psychiatry's are rolling, whereas cardiology's is fixed and decreases per fiscal year.

\section{Planning object}

Tactically, the planning object should refer to the patient group, as in urology, which enables capacity-related adjustments for specific groups. Cardiology's planning has improved control-of-care provision by introducing more specific planning for groups requiring acute care, but lacks the patient group focus for non-acute care patients. In psychiatry, departmental evaluations using key performance indicators (KPIs), patients are aggregated as either new or returning, which prevented capacity planning from providing necessary improvements for specific patient groups. Conversely, urology, evaluated using total visits and surgeries, involves planning that complements patient groups as planning objects with overall total visit and surgery targets, which allow it to both score well per KPI-based evaluations and proactively provide necessary adjustments for patient groups. Psychiatry managers cannot effectively plan adjustments with total patients as planning object.

\section{Activities}

The urology and psychiatry planning activities match the framework, with some differences in timing and forum. Urology completes most activities in single meetings, whereas psychiatry divides them between clinics and the whole department. Since cardiology has annual meetings with random checks throughout the year, it lacks activities like the ones in the framework, thus limiting performance.

\section{Analytical tool}

All three departments use spreadsheets for analytical planning, because weak data exclude more sophisticated tool.

\section{Future demand}

To forecast demand, staff in all three departments use historical data, albeit different kinds. Cardiology's data represent production from the previous year; however, since costs exceed the budget during the fiscal year and outsourcing production on short notice is common, the data are insufficient for forecasting actual demand, which shows that data, unconstrained by production system performance, are needed. Adding tacit knowledge from other clinics to forecast demand is important as seen within the urology department, were such knowledge was used to validate capacity-related adjustments when planning for the summer closure. In psychiatry, planning input demonstrates context-related variations owing to specialisation, because multiple diagnoses lead to no treatment plans being identified or specified for different patient groups. Data are aggregated (total incoming patients, total visits and discharges) and not specific demand for certain resources. Aggregated demand data complicates deducing demand according to patient group. Input deficiency in estimating required capacity results in reactive capacity planning focused on demand-related adjustments.

\section{Available capacity}

Managers in all three departments estimate capacity based on last year's available capacity. In the urology department last year's capacity is used to estimate available capacity input, owing to scant year-over-year variation in staff, equipment and facilities. Psychiatry uses capacity provided by hospital managers - a negotiation between hospital managers and union representatives about daily patients per practitioner. Available capacity, therefore, is daily patients multiplied by employees and their competence, which generates static capacity for 
patients treated during certain periods. Cardiology's planning process uses last year's insufficient capacity as input for the coming year's available resources.

\section{Restrictions}

Allocated budget is seen as a target or a restriction to all three departments and demonstrates the budgeting impact on planning. Managers in each department identifies budget as a restriction, yet each approach it differently. Urology managers use the restriction as a boundary for containing production, whereas psychiatry staff regard it as a limit indicating finances consumed, which reveals possible diversity in perceiving the framework and restrictions. Cardiology and urology staff also use patient waiting time as a restriction and a target.

\section{Targets}

Staff in all three departments formulated targets according to KPIs (e.g., patient waiting time and admission according to medical priority) used by hospital managers to evaluate the production system, along with efficiency targets, including patients delivered per monetary amount and surgeries per year. Urology is evaluated by surgery count and psychiatry by discharge count, which they formulate as respective targets in planning.

\section{Tolerance levels}

Although cardiology uses the restricted budget as a tolerance level, adjustments to stay within budget were made too late to avoid exceeding the budget - perhaps purposely - but which nevertheless indicates that production does not align with demand. Hospital managers set and supervise psychiatry's tolerance levels and provides the department's manager with monthly feedback on production performance per KPIs.

\section{Capacity-related adjustments}

Cardiology's capacity-related adjustments mainly concern adding resources (e.g., subcontractors and extra staff), and small adjustments are made within current resource limits via cross-training and overtime usage. Urology staff focus on adjusting capacity according to demand by moving staff and allocating time between patient groups according to demand; adjustments are made within current resource limits with no subcontractors being added and rarely extra staff. Extra clinic hours are distributed to patient groups needing queue reduction, and adjusting capacity may accommodate adjustment timing, given that senior managers need to approve certain changes. Capacity within psychiatry is adjusted whenever possible, which managers adjust to accommodate demand. Contextual factors such as care given, and resources used, can affect adjustments for both psychiatry and urology; e.g., workforce planning. For psychiatry, the regulations against hiring temporary psychiatrists and the fact that treatment quality relies partly on staffing continuity, limits the capacity adjustment option.

\section{Demand-related adjustments}

Whereas urology focuses on capacity-related adjustments, cardiology and psychiatry focus on demand-related adjustments. Cardiology staff create queues, reroute patients to other providers, and prioritises emergency patients. Psychiatry staff plan admissions, alters visit frequency and reschedule patients.

\section{Feasible production plan}

In cardiology, planning output is a recommendation for next year's production and does not provide a feasible production plan. Urology's and psychiatry's planning processes both 
provide a feasible master production plan. Psychiatry's plan is based on aggregated patients across subdivisions and thus does not support planning at the patient-group level.

\section{Feedback}

In cardiology, output feedback is a budget indicator, not a production plan. By using capacity planning as a production support tool, urology is the most up-to-date department; it also controls production via planning activities and adjusting activities according to variations in capacity and demand. Psychiatry's planning feedback forecasts how the production system is performing according to patient waiting time. The psychiatry planning process output provides production plans and feedback on tolerance levels, and evaluation on previously made demand forecasts.

\section{Cross-case analysis}

Structure and Activities

Managers in the three departments use the planning process differently. Maturity stages (Table I) (Lapide, 2005) demonstrate variation in departmental maturity, and as standardised planning procedures are lacking at the hospital, process maturity depends on the departmental managers' devotion and commitment. In Table I, the cardiology department's process operates at maturity Stage 1; it is inflexible owing to a set planning horizon and infrequent meetings and is not accustomed to controlling the balance between demand and supply. Consequently, department staff cannot clearly assess what capacity is required or where. Its planning process serves as a tool to manage the production system and provide the most care at the given capacity. Infrequent meetings, poor alignment between supply and demand, and few technical solutions leaves considerable room for improvement and benefits in planning and controlling cardiac treatment production.

The urology department's process is the most mature - at least Stage 2 - given that it has frequent structured meetings and uses available data; its meetings even qualify the department's process as Stage 3. Regarding the process interface, plans are made jointly within the departmental units and could be developed to include the relationship with suppliers (e.g., outpatient clinics) and customers (e.g., outpatient clinics and nursing homes).

The psychiatry department's maturity can be categorised as Stage 2, since it has reconciled its routine schedules and demand-related plans. With its two-level planning, psychiatry staff are set to develop a working capacity-planning process that better accommodates its production system than the other departments. Consequently, activities are performed twice but at different detail and scope level, which is set to facilitate a hierarchical planning process. However, the process is at Stage 1 insofar as supply is not aligned with demand.

Technologies used in healthcare, notably hospitals, are not highly developed or integrated. However, this is not as pressing as simpler challenges, including having more valid demand forecasts and improving decision-making about capacity-related adjustments to be timely and unencumbered by bureaucracy.

\section{Input}

Input used by staff in the three departments is diverse. The system's actual demands is vaguely known within the cardiology department, as focus is on input, equipment and budget. There are capacity demand and supply variation data available within the urology department, which is used as input in planning. Concerning available, usable data, the psychiatry department's situation is the opposite; unlike the cardiology department's relatively straightforward technical equipment, capacity estimation in the psychiatry department is difficult. Demand forecasting is difficult; multiple and unclear diagnoses lead 
to missing treatment plans for different patient groups. Psychiatrist shortage and limited patient-doctor interchangeability in response to patients' conditions restricts available capacity. Areas for improvement within the department are data quality, including how to represent psychiatric care processes and define treatment plans for patient groups to estimate demand for different resources.

\section{Adjustments}

Department managers also reveal diverse ways for making capacity and demand-related adjustments. Both the psychiatry and the urology departments cannot increase capacity, owing to psychiatrist and urologist shortages. However, within the urology department, the process is used to alter capacity to accommodate demand despite urologist shortages, which is not the case within the psychiatry department. Compared to the others, cardiology managers adjusts demand primarily by shifting patients' waiting times, and by buying extra capacity from subcontractors. Their planning process does not currently support internal capacity changes.

\section{Output}

No expectations on capacity-planning outcomes are imposed within the cardiology department and planning is used to update budget consumption, which makes reactive shortterm solutions necessary. The urology and psychiatry departments' outputs represent more mature, usable processes that enable managers to shift from reactive to proactive adjustments.

\section{Discussion, conclusions and recommendations}

This study explores tactical planning potential within hospital departments. Through three case studies, we see that an active tactical planning process can exchange costly, short-term demand adjustments for more proactive capacity adjustments that improve possibilities to stay under budget and keep waiting times and queues within limits. Active tactical planning opens more possible adjustments to balance capacity supply with demand. However, maturity and top manager support are critical issues for active tactical planning at department level, and healthcare providers should benefit by focusing efforts on improving planning knowledge and providing planning support to department managers. We show that the most immature department (cardiology), without any active capacity planning, only balances between demand and supply through prolonging queues and using costly suppliers. Urology, the more planning- mature department, had a wider action list to adjust both the capacity and demand side to find a balance. Furthermore, the more mature the department, the less budget restrictions are felt (cardiology). Instead, a mature process sees the budget as a goal and stands ready to use support tools (urology) and adapt the process to fit resources (psychiatry).

Ivert et al., (2015) and Toumikangas and Kaipia (2014) both show that tactical planning processes should be adapted to the context. We show contextual differences between hospital-departments, revealing that within healthcare, there are contextual differences affecting the tactical planning process. Changing treating staff to adjust capacity in the psychiatry department is hard as psychiatric care requires continuity, i.e., same staff treating a certain patient throughout the process. We can also see contextual differences in estimating care demand depending on the care provided. Estimating total visits that a psychiatric patient needs is problematical, making it hard to forecast resource demand. Cardiology and urology staff, on the other hand, find it easier to estimate capacity demand stemming from a certain diagnosis and identify patient or diagnosis groups to serve as planning objects.

Supported by the cases, the framework for tactical capacity planning that we developed (Table II) represents a sound foundation for pinpointing components for inclusion in a 
capacity-planning framework for healthcare providers. No earlier framework for healthcare tactical capacity planning has been identified. The framework structures the planning process and offers recommendations for planning, especially adjustments. Also, adding adjustments to the existing framework (Tavares Thomé et al., 2012) is a contribution as it highlights the tactical planning goal; i.e., balancing demand and supply. Comparing the present process with the framework's content can guide planning choices and prioritisations, particularly regarding process expectations and targets, gauging performance according to the plan, and determining the correspondence between plans and practice. However, the framework provides only components and structure; each department has to assemble its own process for its specific context, as the two-level planning process in the psychiatry department exemplifies. The framework can serve as a tool to identify current planning weaknesses.

Further research is needed to confirm the framework's potential and to identify other contextual issues, such as position in the care flow system and clinic number and type within the department. Our study draws upon three cases from the same hospital; it will be necessary to evaluate the framework in other hospitals and countries, especially since case maturity was so low.

\section{References}

Adan, I. and Vissers, J. (2002), 'Patient Mix Optimisation in Hospital Admission Planning: A Case Study', International Journal of Operations and Production Management, Vol. 22 No. 4, pp. 445-461.

Barratt, M., Choi, T.Y. and Li, M. (2011), 'Qualitative Case Studies in Operations Management: Trends, Research Outcomes, and Future Research Implications', Journal of Operations Management, Vol. 29 No. 4, pp. 329-42.

Beliën, J. and Demeulemeester, E. (2007), 'Building Cyclic Master Surgery Schedules with Leveled Resulting Bed Occupancy', European Journal of Operational Research, Vol. 176 No.2, pp. 1185-1204.

Butler, T., Leong, K. and Everett, L. (1996), 'The Operations Management Role in Hospital Strategic Planning', Journal of Operations Management, Vol. 14 No. 2, pp. 137-156.

Cardoen, B., Demeulemeester, E. and Beliën, J. (2010a), 'Operating Room Planning and Scheduling: a Literature Review', European Journal of Operational Research, Vol. 201 No. 3, pp. 921-932.

Cardoen, B., Demeulemeester, E. and Van der Hoeven, J. (2010b), 'On the Use of Planning Models in the Operating Theatre: Results of a Survey in Flanders', International Journal of Health Planning and Management, Vol. 25 No. 4, pp. 400-414.

de Vries, G., Bertrand, J. and Vissers, J. (1999), 'Design requirements for health care production control systems', Production Planning and Control, Vol. 10 No 6, pp. 559-569.

Drazin, R. and Van de Ven, A.H. (1985), 'Alternative Forms of Fit in Contingency Theory', Administrative Science Quarterly, Vol. 30 No. 4, pp. 514-539.

Eriksson, H., Bergbrant, I.-M., Berrum, I. and Mörck, B. (2011), 'Reducing Queues: Demand and Capacity Variations', International Journal of Health Care Quality Assurance, Vol. 24 No. 8, pp. 592-600.

Grimson, A. and Pyke, D. (2007), 'Sales and Operations Planning: an Exploratory Study and Framework', International Journal of Logistics Management, Vol. 18 No. 3, pp. 322346.

Halvorssen, K. (1992), Samhällsvetenskaplig Metod, Studentlitteratur, Lund.

Hans, E.W., Van Houdenhoven, M. and Hulshof, P.J.H. (2011), 'A Framework for Health Care Planning and Control' Memorandum 1938. 
Hernándes, J.E., Mula, J. and Ferriols, F.J. (2008), 'A Reference Model for Conceptual Modelling of Production Planning Processes', Production Planning and Control, Vol. 19 No 8, pp 725-734.

Ivert, L.K., Dukowska-Popovska, I., Fredriksson, A., Dreyer, H.C. and Kaipia, R. (2015), Contingency between S \& OP Design and Planning Environment', International Journal of Physical Distribution \& Logistics Management, Vol. 45 No. 8, pp. 747773.

Jack, E.P. and Powers, T.L. (2004), 'Volume Flexible Strategies in Health Services: a Research Framework', Production and Operations Management, Vol. 13 No. 3, pp. 230-244.

Jack, E.P. and Powers, T.L. (2009), 'A Review and Synthesis of Demand Management, Capacity Management and Performance in Healthcare Services', International Journal of Management Reviews, Vol. 11 No. 2, pp. 149-174.

Jonsson, P. and Mattsson, S-A. (2003), 'The Implications of Fit between Planning Environment and Manufacturing Planning and Control Methods', International Journal of Operations and Production Management, Vol. 23 No.8, pp. 872-900.

Jonsson, P. and Mattsson, S.-A. (2009), Manufacturing Planning and Control, McGraw-Hill Education, Berkshire.

Lapide, L. (2004), 'Sales and Operations Planning, Part I: The Process', The Journal of Business Forecasting', Vol. 23 No. 3, pp. 17-19.

Lapide, L. (2005), 'Sales and Operations Planning, Part III: A Diagnostic Model', The Journal of Business Forecasting, Vol. 24 No. 1, pp. 13-16.

Larsson, A. and Johansson, M.I. (2007), 'Health Care Planning - A Case Study of a Surgery Clinic', paper in PLANs forsknings- och tilläpnings konferens 2007 5-7 September 2007, Jönköping, Sweden, available at:

https://www.researchgate.net/profile/Agneta_Larsson3/publication/268294888_Healt h_Care_Planning_-

_a_case_study_of_a_surgery_clinic/links/554c89f70cf21ed2135bb20d.pdf (accessed 10 January 2011)

Ministry of Finance. (2010). Budgetpropositionen för 2010. http://www.regeringen.se/rattsdokument/proposition/2009/09/prop.-2009101/

[Accessed 15 May 2014]

Moore, S. (2003), 'Capacity Planning - Modelling Unplanned Admissions in the UK NHS', International Journal of Health Care Quality Assurance, Vol. 16 No. 4, pp. 165-172.

OECD/EU Health at a Glance: Europe 2016, OECD Publishing.

Olhager, J., Rudberg, M. and Wikner, J. (2001), 'Long-term Capacity Management: Linking the Perspectives from Manufacturing Strategy and Sales and Operations Planning', International Journal of Production Economics, Vol. 69 No. 2, pp. 215-225.

Rae, D. (2005), 'Getting Better Value for Money from Sweden's Healthcare System', OECD Economics Department Working Papers. OECD Economics Department Working Papers, Paris.

Rhyne, D. and Jupp, D. (1988), 'Health Care Requirements Planning: a Conceptual Framework', Health Care Management Review, Vol. 13 No. 1, pp. 17-27.

Ridge, J., Jones, S., Nielsen, M. and Shahani, A. (1998), 'Capacity Planning for Intesive Care Units', European Journal of Operational Research, Vol. 105 No.2, pp. 346-355.

Roth, A. and van Dierdonk, R. (1995). 'Hospital Resource Planning Concepts, Feasibility and Framework', Production and Operations Management, Vol. 4 No. 1, pp. 2-29.

Silvester, K., Lendon, R., Bevan, H., Steyn, R. and Walley, P. (2004), 'Reducing Waiting Times at the NHS: Is Lack of Capacity the Problem?', Clinician in Management, Vol. 12 No. 3, pp. 105-111. 
Smith-Daniels, V., Schweikhart, S. and Smith-Daniels, D. (1988), 'Capacity Management in Health Care Services: Review and Future Research Direction', Decisions Sciences, Vol. 19 No. 4, pp. 889-919.

Sousa, R. and Voss, C.A. (2008), 'Contingency Research in Operations Management Practices', Journal of Operations Management, Vol. 26 No. 6, pp. 697-713.

Stiernstedt, G., Ingmanson, A. and Johansson, N. (2016a), 'Våra Förslag för en Effektiv Sjukvård', Dagens Medicin. [Online]. Available: https://www.dagensmedicin.se/artiklar/2016/01/13/vara-forslag-for-en-mer-effektivsjukvard/ [Accessed 20160113].

Stiernstedt, G., Zetterberg, D. and Ingmanson, A. (2016b), Effektiv Vård, Statens Offentliga Utredningar (Official Reports of the Swedish Government), SOU2016:2, Stockholm, Sweden.

Tai, G. and Williams, O. (2008), 'Product Line Management for Health Care System: Theoretic Capacity Planning over Various Resources', IEEM International Conference on Industrial Engineering and Engineering Management 8-11 Dec 2008 Singapore, pp. 690-694.

Tavares Thomé, A., Scavarda, L., Fernandez, N. and Scavarda, A. (2012), 'Sales and Operations Planning: a Research Synthesis', International Journal of Production Economics, Vol. 138 No. 1, pp. 1-13.

Tenhiälä, A. (2011), 'Contingency Theory of Capacity Planning: the Link between Process Types and Planning Methods', Journal of Operations Management, Vol. 29 No. 1-2, pp. 65-77.

Tuomikangas, N. and Kaipia, R. (2014), 'A Coordination Framework for Sales and Operations Planning (S\&OP): Synthesis from the Literature', International Journal of Production Economics, Vol. 154 No. August, pp. 243-62.

Utley, M. and Worthington, D. (2012), 'Capacity Planning', Handbook of Healthcare System Scheduling, Springer, San Fransisco, CA, pp. 11-30.

Vissers, J., Bertrand, J. and De Vries, G. (2001), 'A Framework for Production Control in Health Care Organizations', Production Planning and Control, Vol. 12 No. 6, pp. 591-604.

Willcox, S., Seddon, M., Dunn, S., Eswards, R.T., Pearse, J. and Tu, J.V. (2007), 'Measuring and Reducing Waiting Times: a Cross-national Comparison of Strategies', Health Affairs, Vol. 26 No. 4, pp. 1078-1087.

Figure 1: Tactical planning process

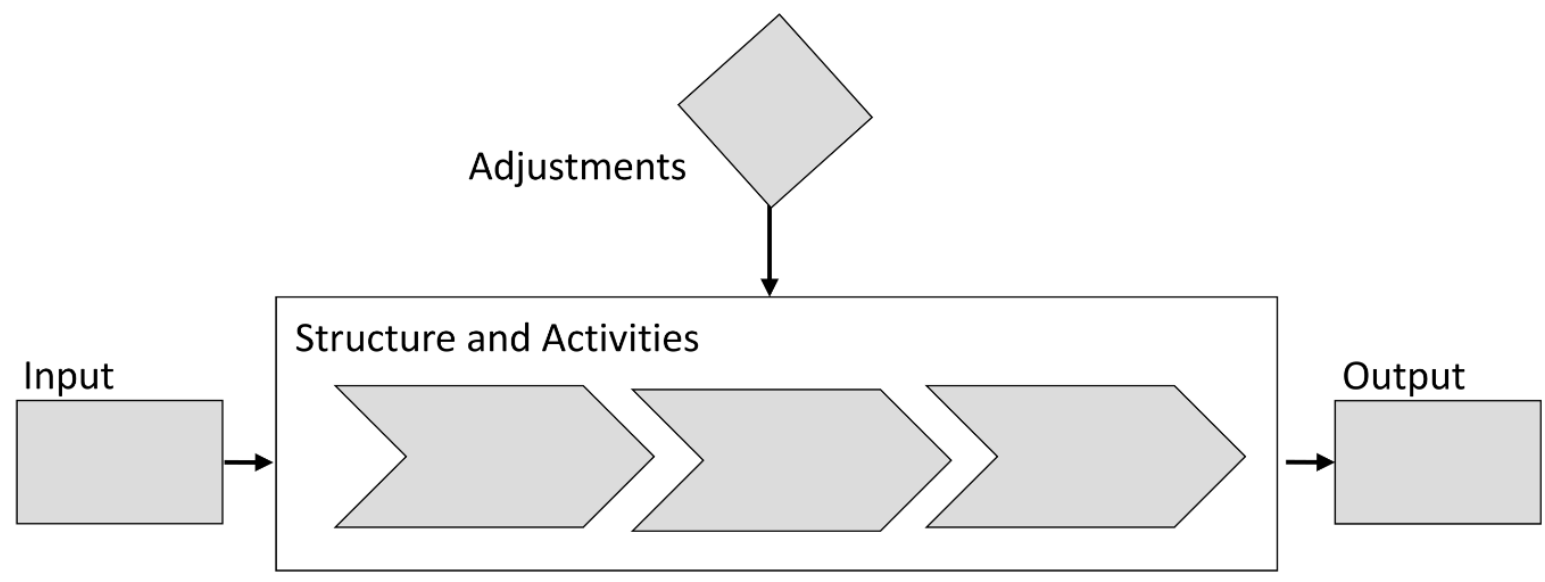

Table I: Planning process - maturity stages 


\begin{tabular}{|c|c|c|c|}
\hline Stage 1: Marginal & Stage 2: Rudimentary & Stage 3: Class & Stage 4: Ideal \\
\hline $\begin{array}{l}\text { Informal meetings } \\
\text { Sporadic scheduling }\end{array}$ & $\begin{array}{l}\text { Formal meetings } \\
\text { Routine schedule } \\
\text { Spotty attendance }\end{array}$ & $\begin{array}{l}\text { Formal meetings } \\
\text { Attendance and } \\
\text { participation should } \\
\text { be } 100 \%\end{array}$ & $\begin{array}{l}\text { Event-driven meetings } \\
\text { Scheduled to consider a } \\
\text { change or discuss a } \\
\text { supply-demand } \\
\text { imbalance }\end{array}$ \\
\hline $\begin{array}{l}\text { Disjointed processes } \\
\text { Separate demand } \\
\text { plans } \\
\text { Supply plans } \\
\text { unaligned to demand } \\
\text { plans }\end{array}$ & $\begin{array}{l}\text { Interfaced processes } \\
\text { Demand plans } \\
\text { reconciled } \\
\text { Supply plans aligned } \\
\text { with demand plans }\end{array}$ & $\begin{array}{l}\text { Integrated processes } \\
\text { Demand and supply } \\
\text { plans aligned } \\
\text { External } \\
\text { collaboration with } \\
\text { limited suppliers and } \\
\text { customers }\end{array}$ & $\begin{array}{l}\text { Extended processes } \\
\text { Demand and supply } \\
\text { plans aligned internally } \\
\text { and externally } \\
\text { External collaboration } \\
\text { with most suppliers and } \\
\text { customers }\end{array}$ \\
\hline $\begin{array}{l}\text { Minimal technology } \\
\text { enablement } \\
\text { Multiple } \\
\text { spreadsheets }\end{array}$ & $\begin{array}{l}\text { Standalone application } \\
\text { interface } \\
\text { Standalone demand } \\
\text { planning system } \\
\text { Standalone multi- } \\
\text { facility APS } \\
\text { Systems interfaced } \\
\text { unilaterally }\end{array}$ & $\begin{array}{l}\text { Applications } \\
\text { integrated } \\
\text { Demand planning } \\
\text { packages and supply } \\
\text { planning applications } \\
\text { integrated } \\
\text { External information } \\
\text { manually integrated }\end{array}$ & $\begin{array}{l}\text { Full set of integrated } \\
\text { technologies } \\
\text { Advanced Sales and } \\
\text { Operations planning } \\
\text { workbench } \\
\text { External-facing } \\
\text { collaborative software } \\
\text { integrated to internal } \\
\text { demand -supply } \\
\text { planning systems }\end{array}$ \\
\hline
\end{tabular}

Table II: Framework for tactical capacity planning within healthcare

\begin{tabular}{|c|c|c|c|}
\hline Structure and Activities & Input & Adjustments & Output \\
\hline $\begin{array}{l}\text { Meetings } \\
\text { Frequency } \\
\text { Participants } \\
\text { Planning horizon } \\
\text { Planning object } \\
\text { Activities } \\
\text { Calculating available and } \\
\text { required capacity } \\
\text { Comparing available and } \\
\text { required capacity } \\
\text { Choose suitable } \\
\text { adjustments considering } \\
\text { targets } \\
\text { Adapt the delivery plan/or } \\
\text { the production plan } \\
\text { Establish delivery plan, } \\
\text { production plan and } \\
\text { actions taken at the } \\
\text { tolerance levels }\end{array}$ & $\begin{array}{l}\text { Future demand } \\
\text { Production plan } \\
\text { based on: } \\
\text { Unconstrained and } \\
\text { consensus-based } \\
\text { forecasts } \\
\text { Downstream demand } \\
\text { Backlog/waiting lists } \\
\text { Available capacity } \\
\text { RCCP- including } \\
\text { anticipated capacity } \\
\text { cut downs } \\
\text { Restrictions } \\
\text { Budget (available } \\
\text { funding) } \\
\text { Strategic planning } \\
\text { Operational } \\
\text { constraints }\end{array}$ & $\begin{array}{l}\text { Capacity adjustments } \\
\text { Overtime } \\
\text { Extra staff } \\
\text { Sub-suppliers, i.e., buy } \\
\text { care from other } \\
\text { healthcare providers } \\
\text { Moving capacity } \\
\text { Cross-training } \\
\text { Demand adjustments } \\
\text { Medical priority } \\
\text { Re-scheduling } \\
\text { Building queues } \\
\text { Admissions planning } \\
\text { Scheduling rules }\end{array}$ & $\begin{array}{l}\text { Feasible production } \\
\text { plan } \\
\text { Feedback } \\
\text { To upper planning } \\
\text { level } \\
\text { To the next planning } \\
\text { round }\end{array}$ \\
\hline
\end{tabular}




\section{Analytical methods}

\section{Targets}

Spreadsheet

IT system support

Throughput (time and volume)

Mathematical models

Waiting time

Waiting list lengths

Resources utilization

Costs (change in

budget)

Tolerance levels 